\title{
Adaptive harvest management of North American waterfowl populations: a brief history and future prospects
}

\author{
James D. Nichols $\cdot$ Michael C. Runge . \\ Fred A. Johnson · Byron K. Williams
}

Received: 31 January 2007/Revised: 11 September 2007/Accepted: 24 October 2007/Published online: 22 November 2007

(C) Dt. Ornithologen-Gesellschaft e.V. 2007

\begin{abstract}
Since 1995, the US Fish and Wildlife Service has used an adaptive approach to the management of sport harvest of mid-continent Mallard ducks (Anas platyrhynchos) in North America. This approach differs from many current approaches to conservation and management in requiring close collaboration between managers and scientists. Key elements of this process are objectives, alternative management actions, models permitting prediction of system responses, and a monitoring program. The iterative process produces optimal management decisions and leads to reduction in uncertainty about response of populations to management. This general approach to management has a number of desirable features and is recommended for use in many other programs of management and conservation.
\end{abstract}

Keywords Adaptive management - Conservation . Decision theory $\cdot$ Harvest management $\cdot$ North America

Communicated by P.H. Becker.

J. D. Nichols $(\bowtie) \cdot$ M. C. Runge

Patuxent Wildlife Research Center,

US Geological Survey, Laurel, MD 20708, USA

e-mail: jnichols@usgs.gov

F. A. Johnson

Division of Migratory Bird Management,

US Fish and Wildlife Service,

Gainesville, FL 32653, USA

B. K. Williams

Cooperative Research Units, US Geological Survey,

Reston, VA 20192, USA

\section{Introduction}

In 1995, the US Fish and Wildlife Service first implemented an adaptive approach to the establishment of sport hunting regulations for mid-continent North American Mallard ducks, Anas platyrhynchos (Nichols et al. 1995; Williams and Johnson 1995; Johnson et al. 1996; Johnson 2001). This approach to harvest management has now been followed for over a decade and represents a unique application of a decision-theoretic approach to management of an animal population over a large geographic scale. In this paper, we argue that adaptive harvest management (AHM) provides a model for avian conservation and management deserving of more widespread application. We then provide a brief review of AHM and conclude with a discussion of future prospects.

\section{Management, conservation and science}

Management and conservation entail decisions and actions, and informed decisions about avian populations will generally require input from ornithologists. Yet these scientists typically play only a peripheral role in management and conservation programs. Recent emphases on avian monitoring programs worldwide suggest that many ornithologists view engagement in monitoring as their primary role in conservation and management. However, monitoring should not be equated with either management or science and is instead best viewed as an important component of these larger processes (Yoccoz et al. 2001; Nichols and Williams 2006).

The contribution of scientists to the management and conservation of animal populations frequently appears to follow a two-step process. First, the scientist collects information or conducts science and provides results to 
managers. Managers are then expected to use these results to make wise decisions. Interactions between managers and scientists are frequently restricted to this transfer of information. Because decision processes in animal management and conservation are always characterized by uncertainty (see below), managers often ask scientists to provide more information or perhaps establish additional monitoring programs. We view this two-step approach to management as inefficient, at best, and we believe that it often will fail to produce wise management decisions.

We prefer an integrated approach in which the manager and scientist collaborate in the process of making management decisions. Under such an integrated approach, scientists focus their data collection on precisely the information expected to be most useful to the management decision. Similarly, science is focused on hypotheses about how the managed system responds to management actions. The adaptive harvest management (AHM) approach to managing the sport harvest of North American waterfowl represents such an integrated process and provides a nice model for structured decision-making for animal conservation and management.

\section{Structured decision processes}

The primary sources of difficulty in making management decisions for ecological resources are (1) disagreement about appropriate management objectives and (2) uncertainty. We recognize four categories of uncertainty in the management of animal populations and communities (e.g., Williams et al. 2002). First, ecological or structural uncertainty refers to the usual situation in which system dynamics and, in particular, responses to management actions are not completely known. Second, environmental variation represents an important source of uncertainty in all natural systems. Third, managers typically face the issue of partial controllability, in which management actions are applied only indirectly, and immediate effects of actions are characterized by uncertainty. Finally, partial observability refers to the manager's inability to directly observe the state of nature. Instead, system state must be estimated, with resulting estimates characterized by uncertainty.

Structured decision processes in general, and adaptive management in particular, are useful approaches to dealing with these difficulties. The elements of such a process include an explicit statement of objectives, a set of available management actions, models of system response to management actions providing a basis for prediction, and a monitoring program to estimate system state and other relevant variables. Below, we consider these elements for the AHM process and then describe the process itself.
AHM for mid-continent Mallards (Anas platyrhynchos)

\section{Elements}

\section{Objectives}

Decision processes are predicated on the development of objective functions that represent formal statements of objectives. The objectives of AHM are to maximize long term cumulative harvest utility, defined as the product of harvest $\left(H_{t}\right.$, number of ducks harvested in year $\left.t\right)$ and the value of harvest $\left(u_{t}\right)$, e.g.,

$\max \sum_{\tau=t}^{T} u_{\tau} H_{\tau}$,

where $T$ is some time in the distant future. The use of a long-term time horizon insures a conservation ethic in assigning value to harvest in the distant future. In addition, the utility $\left(u_{t}\right)$ is written as a function of expected breeding population size in year $t+1$ (e.g., Runge et al. 2006), effectively devaluing harvest that is expected to produce population sizes below the goal expressed in the North American Waterfowl Management Plan (US Department of the Interior and Environment Canada 1986).

\section{Management alternatives}

Management and conservation involve the implementation of management actions pursuant to the achievement of objectives. Alternative actions should produce different benefits and costs, and the set of alternative actions should remain static for some period of time, in order to provide an opportunity to learn about their effects. The regulatory alternatives of AHM consist of three regulations "packages" corresponding to liberal, moderate and conservative hunting regulations (e.g., US Fish and Wildlife Service 2007). The packages specify daily bag limits (daily harvest per hunter) and season lengths for each of the four waterfowl flyways (Atlantic, Mississippi, Central, Pacific) representing the administrative units for harvest regulations. The management decision each year is to select a regulatory package in August (e.g., Blohm 1989) preceding the hunting season (typically September-January). Partial controllability is an important source of uncertainty in waterfowl harvest management, as there is substantial variation in the harvest rates produced by a specific set of regulations (e.g., US Fish and Wildlife Service 2007).

The development of both objectives and alternative actions requires input from all relevant stakeholders. Managers and scientists can contribute to the development of objectives and actions, and social scientists may be especially useful in eliciting stakeholder responses. 
However, objectives and alternatives represent stakeholder value judgments and are thus subjective in nature. The development of AHM objectives has involved numerous discussions ranging from considerations of how to evaluate hunter satisfaction to the desirability of incorporating North American Waterfowl Management Plan population objectives via the harvest utility function (e.g., Johnson and Case 2000; Runge et al. 2006). Similarly, habitat management can also contribute to waterfowl management objectives, even though harvest management specifically involves harvest alternatives. This recognition has appropriately led to calls for an integrated and coherent approach to harvest and habitat management (Johnson et al. 1996; Runge et al. 2006).

\section{Predictive models}

Management decisions require predictions about the effects of management actions on system behavior. Waterfowl harvest management thus requires models predicting the population changes expected to result from implementation of different sets of harvest regulations. Structural uncertainty about the response of Mallard populations to harvest regulations led to the development of four models for midcontinent Mallards (Johnson et al. 1993, 1997; US Fish and Wildlife Service 2007). These models represent combinations of two models reflecting different levels of densitydependence of Mallard reproductive rates, and two models reflecting maximal and minimal effects of hunting mortality on total annual survival. The description of these models is beyond the scope of this paper, but they capture key sources of uncertainty in Mallard population responses to harvest.

Each of the four models in AHM is accompanied by a model weight associated with the relative degree of faith in its predictions. The four weights, which are calibrated so that they sum to one, determine the relative influence of each model in identifying the optimal action to take at each decision point. When the program began in 1995, uncertainty was substantial and stakeholder opinions were diverse, so model weights were initially set to be 0.25 . Since then the weights have evolved, as a result of the predictive abilities of the corresponding models (see below, Fig. 1).

\section{Monitoring}

The final component of an informed decision process is a monitoring program for estimation of system state variables and related rate parameters. The US Fish and Wildlife Service, Canadian Wildlife Service, and various

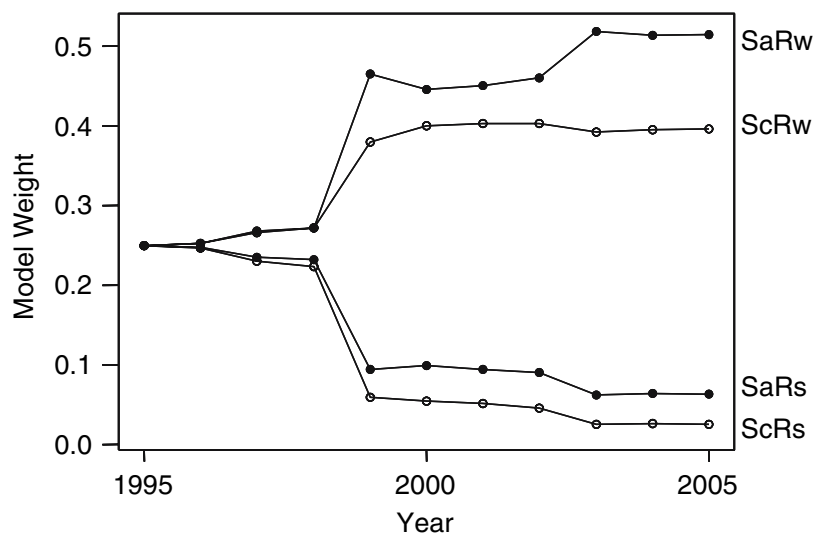

Fig. 1 The evolution of weights for models of mid-continent Mallard ducks (Anas platyrhynchos) (SaRw additive mortality and weakly density-dependent recruitment, $S c R w$ compensatory mortality and weakly density-dependent recruitment, SaRs additive mortality and strongly density-dependent recruitment, $S c R s$ compensatory mortality and strongly density-dependent recruitment). Source: US Fish and Wildlife Service (2007)

state, provincial and private partners carry out a number of relevant monitoring programs (e.g., Martin et al. 1979; Nichols et al. 1995). The Breeding Waterfowl and Habitat Aerial Survey provides estimates of breeding population size and number of wetlands in May for most of the Canadian and US breeding grounds where mid-continent Mallards are produced (Smith 1995). This survey is based on a systematic sampling design and includes a ground survey component to estimate the fraction of birds missed from the air. Both Canada and the US conduct national harvest surveys to estimate the number of harvested birds. Large-scale banding programs are used to estimate annual survival and harvest rates. These estimates are used to periodically update model relationships (e.g., between hunting regulations and resulting harvest rates) and can also be used to compare against model predictions for the purpose of updating model weights. A key point about these monitoring programs is that they were designed specifically to inform harvest decisions and thus retain a management focus and relevance lacking in many animal monitoring programs.

\section{Process}

The formal adaptive management process adopted in 1995 uses these decision elements in an annual cycle of decision making and analysis. In late summer (July-August) of each year a decision must be made about the hunting regulations to be implemented in the upcoming hunting season. Preseason estimates of Mallard breeding population size and available wetlands represent the state of the system at that time. Along with the objective function and the population 
models and model weights, these estimates are incorporated in a stochastic dynamic optimization algorithm (Lubow 1995; Williams 1996) to produce the optimal set of hunting regulations. Ideally, the hunting regulations identified by this process are then implemented during the subsequent hunting season.

In the following spring, Mallard population size and wetland numbers are again estimated, and the population estimate is used to estimate new model weights. Basically, these weights increase for models whose predictions the previous year are more consistent with the new estimate of population size, and the weights decrease for models that predicted poorly. More specifically, the model weight for model $i$ in year $t+1, \operatorname{Pr}$ (model $i \mid$ data $\left._{t+1}\right)$, is computed, based on Bayes theorem, as:

$\operatorname{Pr}\left(\right.$ model $i \mid$ data $\left._{t+1}\right)=\frac{\operatorname{Pr}(\text { model } i) \operatorname{Pr}\left(\text { data }_{t+1} \mid \text { model } i\right)}{\sum_{j} \operatorname{Pr}(\operatorname{model} j) \operatorname{Pr}\left(\text { data }_{t+1} \mid \operatorname{model} j\right)}$,

where $\operatorname{Pr}\left(\right.$ data $_{t+1} \mid$ model $\left.i\right)$ is the probability of the new data (i.e., the new abundance estimate) given model $i$ (equivalent to the likelihood under model $i$ ) and $\operatorname{Pr}$ (model $i$ ) is the prior probability of model $i$. These changes in model weights reflect learning and represent the evolution of our understanding about system dynamics and responses to management actions (Johnson et al. 2002).

As an example, the trajectories of model weights associated with the models for mid-continent Mallards are shown in Fig. 1. Models represent large (Sa) and small (Sc) effects of hunting on annual mortality rates, and weak ( $\mathrm{Rw}$ ) and strong (Rs) density dependence of reproductive rates (Johnson et al. 1997; US Fish and Wildlife Service 2007). All four models (representing all four combinations of these models for reproductive and survival rates) were given equal weights in 1995. Several subsequent years provided little information relevant to model discrimination, whereas 1998 and 2003 were relatively informative years. Current model weights reflect support for weak density dependence of reproductive rates and still admit substantial uncertainty about survival rate modeling. The evolution of model weights, reflecting learning about the best approximating models of system behavior, is a key strength of AHM.

Returning to the process, the updating of model weights is carried out as soon as the May survey results become available. The new model weights and new estimates of system state are then used in conjunction with the models, objectives and management actions to select the most appropriate regulations for the next hunting season.

Stakeholders may periodically wish to modify or develop new program objectives, as perspectives and values evolve during the course of managing through time. Similarly, scientists and managers may conclude that existing models should be modified or new models developed as learning progresses. These kinds of structural changes are certainly possible, with the caveat that learning about model predictive abilities is accelerated by allowing several iterations of comparing predictions and observations after the structural changes are made. An implication is that the alteration of objectives, models, and management alternatives should be considerably less frequent than the annual changes in regulations.

\section{Discussion}

The adoption of a formal adaptive management approach to dealing with the harvest of mid-continent Mallards has been successful in several respects and has thus survived politically and institutionally for well over a decade. During this period, mid-continent Mallard breeding population estimates have fluctuated between about 6 million and nearly 12 million birds (Fig. 2; also see US Fish and Wildlife Service 2007), with an estimate of over 9 million for 2007. Perhaps most importantly, management decisions have been transparent. The entire process is well documented, and the basis for each regulatory decision is clearly presented (e.g., US Fish and Wildlife Service 2007). An important result of the transparent and objective process is that disagreements have appropriately shifted from topics that conflated ecological uncertainty, partial controllability and objectives, to a clear focus on objectives and management alternatives.

Adaptive management has also led to a reduction in ecological uncertainty (Fig. 1), although this reduction must be qualified. Substantial progress has been made in learning which of the four a priori models of Mallard

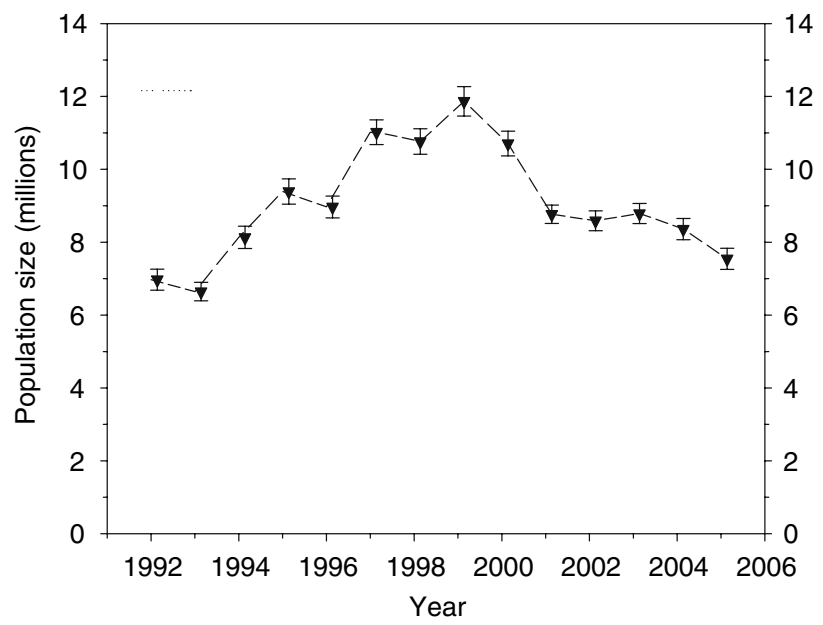

Fig. 2 Breeding population size estimates for mid-continent Mallards. Error bars represent 1 standard error. Source: US Fish and Wildlife Service (2007) 
population dynamics and responses to management are the best predictors. Such progress is very important from a management perspective.

Nevertheless, predictive ability does not necessarily correspond to ecological understanding (Johnson et al. 2002). The current models of density-dependence are not as mechanistic (sensu Williams et al. 2002) as we might like. For example, actual ecological mechanisms for densitydependent reproduction and mortality typically must involve the number of birds relative to some critical resource(s). Even if the key variables of mechanistic relationships are identified, the functional forms of such relationships can also be very important (Johnson et al. 2002; Runge and Johnson 2002). Multiple functional forms may appear to fit well across the range of available data, yet yield different optimal policies (Runge and Johnson 2002).

In addition, it is necessary to effectively and efficiently monitor resources, so as to identify useful hypotheses and incorporate them into predictive models. It is through the comparison of hypothesis-based model predictions against monitoring data that hypotheses are investigated. If the predictive abilities of the models appear to vary over time in a nondirectional manner, examination of the model set for key missing variables or poorly specified functional relationships is warranted. In that case, it may be necessary to alter the models in the model set, or incorporate new models that are designed to accommodate these changes.

Recent and ongoing efforts associated with adaptive management of mid-continent Mallards include revisiting objectives and management actions, with recognition of the need for coherence between, and eventually integration of, harvest and habitat management actions (Runge et al. 2006). Adaptive management of Mallards has expanded to deal with eastern Mallard stocks as well as mid-continent birds. Models are currently being developed for western Mallards as well. Efforts are also underway to develop adaptive management programs for Pintails (Anas acuta), American Black Ducks (Anas rubripes), Greater and Lesser Saup (Aythya marila, A. affinis), and Atlantic population Canada Geese (Branta canadensis) (e.g., US Fish and Wildlife Service 2007; Hauser et al. 2007).

A number of useful lessons have been learned about harvest management during the initial decade of the application of the adaptive management process. A lesson that is perhaps obvious, but worth stating, is that many management strategies are biologically sustainable. Optimality is thus determined by objectives and management constraints, the elements of the process reflecting stakeholder input and societal values. Eliciting and balancing stakeholder values and opinions is an important, and perhaps underappreciated, step in any management process.

In this regard, "double-loop learning" (Lee 1993; Williams et al. 2007) has become important in discussions about AHM (Runge et al. 2006; Johnson 2006). The original objective function and model set established in 1995 have remained in place to present, but the cumulative experience has raised questions about whether the decision process is appropriately structured. Discussions that have ensued have focused particularly on the objective function, whether a "shoulder strategy" would be more appropriate than the current devaluation method, and whether waterfowl harvest and habitat management objectives need to be integrated (Runge et al. 2006). In other words, AHM, like other applications of adaptive management (Lee 1993), has recognized that periodic renewal outside of the normal process of technical adaptation is necessary to maintain stakeholder and political support.

Another lesson involves the limits placed on management by partial controllability and the uncertainty associated with application of management actions. One underappreciated result of this limitation is that efforts to fine-tune management to exploit additional small sources of variation in harvest potential (e.g., of waterfowl stocks) is likely to have large costs and only marginal benefits (also see Nichols and Johnson 1989; Johnson and Case 2000; Johnson 2006).

In conclusion, the adaptive management approach to the harvest of mid-continent Mallards has been successful in many respects and provides a model for other management and conservation efforts. The approach was developed to be useful in the face of the uncertainty that characterizes the management of any natural system. The approach represents a joint endeavor of managers and scientists that is far preferable to the two-step approach that typically characterizes the interaction of these two groups. We recommend serious consideration of adaptive management approaches for application to the many conservation and management challenges currently facing natural resource managers worldwide.

Many European waterfowl managers and ecologists have called for an adaptive approach to the management of European duck harvest (e.g., Elmberg et al. 2006). Despite such recommendations, our discussions with some European waterfowl managers lead us to conclude that many managers misunderstand the process of adaptive management to the extent that they believe the approach could not be usefully implemented in Europe. Here, we consider these comments.

A frequent comment is that North American waterfowl management involves three countries and two languages, whereas European waterfowl management involves a large number of countries, languages, and hunting traditions. The claim is that this variation within Europe precludes agreement on a framework for management, such that agreement on objectives and management actions, for example, would be impossible to attain. If agreement on 
these management elements is indeed impossible, then an adaptive approach to management can still be taken within each country or group of countries for which some agreement is possible. In such a case, the actions of nonparticipating countries would be basically viewed as components of environmental variation, in the sense of uncontrollable and possibly even unpredictable effects on populations. The central point is that any country or group of countries claiming interest in management could choose to manage and follow an adaptive approach in doing so.

Other comments emphasize variation among European countries in hunting regulations and systems, and in magnitudes of harvest. Such comments do not appear to appreciate the geographic variation that exists within North America in regulations packages (these vary among the North American flyways), in timing of open seasons, and in magnitudes of harvest. Adaptive harvest management does not require geographic uniformity in regulations or harvest, but instead represents an extremely flexible approach that can readily accommodate geographic variation.

Additional comments are that European waterfowl monitoring programs are not nearly as well developed as those established in North America, and that much less is known about populations in Europe than in North America. While these comments may be true, they do not argue against the use of adaptive management. Some sort of monitoring is indeed necessary for adaptive management, but precise estimates of population size and all demographic rate parameters are not a requirement. Similarly, because of its emphasis on learning, adaptive management is actually more important for poorly known systems than for those that are well understood. Adaptive management simply provides a means of managing in a manner that is optimal with respect to knowledge about the managed system.

In summary, we believe that recommendations such as those by Elmberg et al. (2006) to initiate an adaptive approach to duck harvest management in Europe is a good one. We have heard many arguments that adaptive approaches to population management are not possible in Europe, but we find these arguments to be largely without basis. In contrast, the arguments in favor of adaptive management are compelling and should lead to strong consideration of this approach.

Acknowledgments We thank Stephen Baillie and Fernando Spina for the invitation to present this paper. We thank Franz Bairlein, Peter Becker, and Matthieu Guillemain for constructive comments on an earlier draft of this manuscript.

\section{References}

Blohm RJ (1989) Introduction to harvest-understanding surveys and season setting. Proc Int Waterfowl Symp 6:118-133
Elmberg J, Nummi P, Poysa H, Sjoberg K, Gunnarsson G, Clausen P, Guillemain M, Rodrigues D, Vaananen V-M (2006) The scientific basis for new and sustainable management of migratory European ducks. Wildl Biol 12:121-128

Hauser CE, Runge MC, Cooch EG, Johnson FA, Harvey WF IV (2007) Optimal control of Atlantic population Canada geese. Ecol Modell 201:27-36

Johnson FA (2001) Adaptive regulation of waterfowl hunting in the United States. In: Stahl RG Jr, Bachman RA, Barton AL, Clark JR, deFur PL, Ellis SJ, Pittinger CA, Slimak MW, Wentsel RS (eds) Risk management: ecological risk-based decision-making. SETAC Press, Pensacola, pp 113-131

Johnson FA (2006) Adaptive harvest management and double-loop learning. Trans N Am Wildl Nat Resour Conf 71 (in press)

Johnson FA, Case DJ (2000) Adaptive regulation of waterfowl harvests: lessons learned and prospects for the future. Trans $\mathrm{N}$ Am Wildl Nat Resour Conf 65:94-108

Johnson FA, Williams BK, Nichols JD, Hines JE, Kendall WL, Smith GW, Caithamer DF (1993) Developing an adaptive management strategy for harvesting waterfowl in North America. Trans N Am Wildl Nat Resour Conf 58:565-583

Johnson FA, Williams BK, Schmidt PR (1996) Adaptive decisionmaking in waterfowl harvest and habitat management. Proc Int Waterfowl Symp 7:26-33

Johnson FA, Moore CT, Kendall WL, Dubosky JA, Caithamer DF, Kelley JR Jr, Williams BK (1997) Uncertainty and the management of mallard harvests. J Wildl Manage 61:202-216

Johnson FA, Kendall WE, Dubovsky JA (2002) Conditions and limitations on learning in the adaptive management of mallard harvests. Wildl Soc Bull 30:176-185

Lee KN (1993) Compass and gyroscope: integrating science and politics for the environment. Island Press, Washington

Lubow BC (1995) SDP: generalized software for solving stochastic dynamic optimization problems. Wildl Soc Bull 23:738-742

Martin F, Pospahala RS, Nichols JD (1979) Assessment and population management of North American migratory birds. In: Cairns J, Patil GP, Waters WE (eds) Environmental biomonitoring, assessment, prediction, and management certain case studies and related quantitative issues. Statistical ecology, vol Sll. International Co-operative Publishing House, Fairland, pp 187-239

Nichols JD, Johnson FA (1989) Evaluation and experimentation with duck harvest management strategies. Trans N Am Wildl Nat Resour Conf 54:566-593

Nichols JD, Williams BK (2006) Monitoring for conservation. Trends Ecol Evol 21:668-673

Nichols JD, Johnson FA, Williams BK (1995) Managing North American waterfowl in the face of uncertainty. Annu Rev Ecol Syst 26:177-199

Runge MC, Johnson FA (2002) The importance of functional form in optimal control solutions of problems in population dynamics. Ecology 83:1357-1371

Runge MC, Johnson FA, Anderson MG, Koneff MD, Reed ET, Mott SE (2006) The need for coherence between waterfowl harvest and habitat management. Wildl Soc Bull 34:1231-1237

Smith GW (1995) A critical review of the aerial and ground surveys of breeding waterfowl in North America. US Department Interior, Biological Science Report 5. Washington, DC

US Department of the Interior and Environment Canada (1986) North American waterfowl management plan. US Department Interior, Washington, DC

US Fish and Wildlife Service (2007) Adaptive harvest management: 2007 hunting season. US Department Interior, Washington, DC (http://www.fws.gov/migratorybirds/reports/ahm06/2007-AHMreport(final2).pdf) 
Williams BK (1996) Adaptive optimization and the harvest of biological populations. Math Biosci 136:1-20

Williams BK, Johnson FA (1995) Adaptive management and the regulation of waterfowl harvests. Wildl Soc Bull 23:430-436

Williams BK, Nichols JD, Conroy MJ (2002) Analysis and management of animal populations. Academic, San Diego
Williams BK, Szaro RC, Shapiro CD (2007) Adaptive management: the US Department of the interior technical guide. Adaptive Management Working Group, US Department of the Interior, Washington, DC

Yoccoz NG, Nichols JD, Boulinier T (2001) Monitoring of biological diversity in space and time. Trends Ecol Evol 16:446-453 